\section{But do they learn anything?}

SIR-Michael Shortland (Nature 328, 213; 1987) used as part of his argument about the limitations of interactive science centres a quotation attributed to me in a daily newspaper. He then proceeded to question in a facile manner the validity of what Techniquest, and indeed other interactive centres, are trying to do. I am well aware of the difficulties to which he draws attention, but a balanced discussion of these difficulties is not necessarily the main interest of a journalist in the limited space and context of a short article in a daily newspaper.

I therefore offer a longer quotation from the "Director of Techniquest" (myself):

So visitors to interactive science and technology centres enjoy themselves. But do they learn anything? We all have a fund of anecdotes to illustrate that learning can occur, and many of us have the faith that the fun and enjoyment could well be a vehicle for allieviating the alienation from science felt by many people

[However] we have not yet invented a ufficiently diverse menu of programmes, methods and devices which can be incor porated into a coherent educational strategy whereby visitors would be allowed, enabled and encouraged to learn more if they so choose.

The task is to create the dishes on this menu and to implement educational strategies based on them. Only then will interactive exhibits deserve to be called 'plores' and interactive science and technology centres be able to fulfill their potential as part of the non-formal education scene.

JOHN BEETLESTONE

Department of Education,

University College,

Cardiff CF2 $4 A G, U K$

SIR-Michael Shortland's comments (Nature 328, 213; 1987) on hands-on learning with interactive demonstrations and experiments, as in the Exploratory in Bristol, point to potentially exciting educational research. What indeed do visitors actually learn hands-on? Can ordinary people in such an environment discover truths of science for themselves? Can effective learning be fun, even to playing games? Perhaps we will find some answers in the Exploratory.

It is delightful watching families playing with the 'plores', for exploring, and questioning and explaining phenomena to each other. Their behaviour sometimes looks random, sometimes directed, but seldom totally inappropriate or destructive. It is hard to believe that learning has to be a solemn business, though quiet places for thought are essential.

Bertrand Russell's distinction between knowledge by acquaintance and knowledge by description sets up the significance, and also difficulties of presenting science hands-on. Experiencing the forces of a large gyroscope is 'acquaintance' more evocative than any words; but it needs concepts and words to explain, for example, the precision of a gyroscope (Newton's first law, point masses) or to explain how images are formed, or why mirrors reflect. It is not clear how as children we move from experience to understanding, with concepts and propositions of language. Here the difficulties for any science museum start, for children, and most adults, simply do not have the necessary background concepts for explanations to be meaningful. We attribute this to the lack of exploratories over the past many years.

Successful exhibits or plores evoke some surprise. Surprising experience carries information, and suggests questions. Questioning, in turn, leads to seeking explanations and concepts which, especially when shared, may be expressed in words. Without shared experience and some understanding, the explanations which through brevity lack the lead-uns and helpful hints of books - may be totahy meaningless, however well written. This is like the neurological condition of agnosia ('lack of knowledge') which renders perception meaningless even though the eyes are not optically blind. The significance of phenomena and principles of how things work are simply invisible without necessary knowledge. The aim of exploratories is to cure the agnosia of virtually the entire population, by offering first-hand acquaintance of phenomena, and principles of science and technology, mainly through simple experiments and games. It is indeed remarkable that people willingly pay to play with pendulums, to discover underlying principles such as inertia and gravity. The hope is that through this interactive experience, many people will lose their agnosia blindness as they gain the knowledge and concepts necessary for seeing as science understands.

It turns out that plores on how we see and understand - including illusions of various kinds - can be particularly effective as they bridge experience and physics. We may hope that hands-on exploring leads to using the words and special symbols of science fluently, as acquaintance with phenomena grows to friendship with the world out there waiting to be discovered.

RiCHARD GREGORY (Hon. Science Director)

The Exploratory, Queen's Road, Victoria Rooms, Clifton, Bristol, UK

\section{Animal models}

SIR-In the News and Views item 'Ironies of animal modelling', J.D. Hallonquist and N. Mrosovsky follow carefully the psychiatric tradition of post hoc reasoning in their attempts to justify the use of animal models in the study of seasonal depression (Nature 329, 18; 1987). After admitting to the physiological inadequacy of the animal model, that is, ". . . it seems likely that the mechanisms for these [human] therapeutic effects are very different from those operating in the photoperiodic animal models...", and the very real possibility of the placebo effect, the authors simply accept the efficacy of the treatment. "Now", they seem to reason, "given the veridicality of the treatment, the use of the animal models must have been responsible". I can only hope this rebuttal reaches them before the advent of winter destroys the final threads of their precarious logic.

To my knowledge, the Hawthorne study remains the classic example of the placebo effect. If Hallonquist and Mrosovsky insist on argument by analogy, I suggest they re-read this study (under very bright light, of course) and leave the human-animal analogue to the equally implausible but more phenotypically congruent hypotheses of the physiologist.

DONALD J. BARnES

The National Anti-Vivisection Society,

112 North Carolina Avenue, SE,

Washington, DC 20003, USA

\section{Conservation laws}

SIR-We who are, so to speak, your lay readers, must thank you for reporting (Nature 328, 755; 1987) the flurry among the high priests of physics on how to interpret the conservation laws for mass and energy. You seem to suggest that the correspondence in Physics Bulletin "has been closed" because it will not do for the acolytes, not to mention the general public, to hear the squabbling.

The need for care in the formulation of the conservation laws is well expressed in R. O. Kapp's last book Towards a Unified Cosmology (Hutchin-son, 1960). Kapp was a distinguished engineer and teacher, well acquainted with relativity theory. $\mathrm{He}$ offers two statements for the principle of conservation of energy, the second of which reads: "The total energy in a selfcontained system is constant."

$\mathrm{He}$ is, however, at pains to distinguish between a "self-contained" and an "isolated" system. In Kapp's view, the material Universe should not be regarded as a self-contained system. "This is just one of the many sly hypotheses that cause misconceptions. They enter our deliberations so unobtrusively that their entry passes unobserved. Thereupon they clothe themselves in the garments of an irrefutable fact. The disguise is often so excellent that even the most critical do not penetrate it." D. H. TOMPSETT 34 Vicarage Road, Henley on Thames, Oxfordshire RG9 $1 \mathrm{HW}, \mathrm{UK}$ 